\title{
Iron-Restricted Erythropoiesis in Anaemic Patients with Giant Cell Arteritis and Polymyalgia Rheumatica
}

\section{Torbjörn Karlsson}

Department of Haematology, Uppsala University Hospital, Uppsala, Sweden.

Email: Torbjorn.A.Karlsson@akademiska.se

Received December $18^{\text {th }}, 2012$; revised January $20^{\text {th }}, 2013$; accepted February $1^{\text {st }}, 2013$

\begin{abstract}
The aim of this observational study was to biochemically characterize the anaemia in GCA (giant cell arteritis) and PMR (polymyalgia rheumatica) patients. Values for mean corpuscular volume, mean corpuscular hemoglobin and soluble transferrin receptor were normal, whereas serum iron and total iron binding capacity (TIBC) were subnormal, and mean ferritin was above the upper reference limit. Iron-restricted erythropoiesis (IRE), defined as a bone marrow smear staining positive for iron in combination with transferrin saturation less than $20 \%$, was present in all patients. All patients exhibited clinical and biochemical signs of active inflammation with elevated C-reactive protein and an increased erythrocyte sedimentation rate.
\end{abstract}

Keywords: Anaemia; Iron-Restriction; Erythropoiesis; Giant Cell Arteritis; Polymyalgia Rheumatica

\section{Introduction}

Anaemia in diseases that induce an inflammatory response, e.g. cancer, infection and rheumatic diseases, is commonly caused by iron-restricted erythropoiesis (IRE), i.e., iron is not available for erythropoiesis since it is sequestered in reticuloendothelial system macrophages by Interleukin-6 dependent hepcidin degradation of ferroportin, the sole transmembrane iron exporting protein [1-5]. Hepcidin-induced ferroportin degradation in enterocytes also reduces uptake of dietary iron, which further restricts erythropoiesis. In the nephrology setting, IRE is commonly known as functional iron deficiency (FID) and seen in anaemic chronic kidney disease (CKD) patients receiving erythropoiesis stimulating agents (ESAs) [6]. In these patients, an ESA-driven supraphysiological erythropoiesis is restricted by the delivery of iron to the bone marrow erythroblasts, which sometimes leads to ESA hyporesponsivness. This condition can be successfully treated by intravenous (iv) iron supplementation [6], which also augments the effect of ESA treatment in cancer patients [7]. Giant cell arteritis (GCA) and polymyalgia rheumatica (PMR) are biochemically characterized by a marked inflammatory response in the form of anaemia, thrombocytosis, an elevated erythrocyte sedimenttation rate (ESR) and increased C-reactive protein (CRP) [8]. Anaemia is common in GCA and PMR and can be the only presenting finding [9-11]. The aim of this observational study was to biochemically characterize the anaemia in GCA and PMR patients.

\section{Material and Methods}

This observational study on blood and bone marrow samples collected during routine anaemia investigation was conducted at the Department of Medicine, Capio Sankt Görans Hospital, Stockholm, Sweden. Six anemic patients who fulfilled the diagnostic criteria for giant cell arteritis $(n=4)[12]$ or polymyalgia rheumatica $(n=$ 2) [8] were included. Anaemia was caused by an inflamematory response in all patients. Other causes of anaemia such as B12, folate or iron deficiency were excluded. None of the patients suffered from renal failure, hypothyreoidism or haemolysis. Leukemia, lymphoma, myelodysplastic syndromes and myeloma were excluded by bone marrow examination. All procedures were in accordance with the Helsinki declaration of 1964. None of the patients received iron supplementation or had received red blood cell transfusion before inclusion. Haematological data, biochemical iron status, CRP and ESR were analysed in all patients. Bone marrow smears were stained by the May-Grunwald-Giemsa method and bone marrow iron stores investigated using Prussian blue staining. Complete blood counts were performed using the ADVIA 2120 analyzer (Siemens Diagnostics, Deerfield, IL, USA). CRP, iron and total iron binding capacity (TIBC) were determined by means of ADVIA 2400 and soluble transferrin receptor (sTfR) using BN ProSpec (Siemens Diagnostics, Deerfield, IL, USA). Ferritin was analysed using ADVIA Centaur XP. All reagents were from Siemens Diagnostics, with the exception of the 
TIBC assay, which was produced by Dakopatts (Dakopatts, Dorchester, UK). Laboratory reference values for $\mathrm{Hb}$ are $>134 \mathrm{~g} / \mathrm{L}$ for men and $>117 \mathrm{~g} / \mathrm{L}$ for women, mean corpuscular volume (MCV) 82 - $98 \mathrm{fL}$, mean corpuscular haemoglobin (MCH) 27 - $33 \mathrm{pg}$, iron 9 - 34 $\mu \mathrm{mol} / \mathrm{L}$, TIBC $47-80 \mu \mathrm{mol} / \mathrm{L}$, transferrin saturation (TSAT) $15 \%-60 \%$ for men and $10 \%-50 \%$ for women, ferritin $20-375 \mu \mathrm{g} / \mathrm{L}$ for men and $7-120 \mu \mathrm{g} / \mathrm{L}$ for women, $\mathrm{CRP}<5 \mathrm{mg} / \mathrm{L}$, sTfR $0.8-1.7 \mathrm{mg} / \mathrm{L}$ and ESR $<20 \mathrm{~mm}$. TSAT is calculated by the formula: (iron/TIBC) $\times 100$. IRE is commonly defined as TSAT $<20 \%$ in combination with ferritin $>100 \mu \mathrm{g} / \mathrm{L}[6,13]$, but in this trial it was defined as TSAT $<20 \%$ in combination with a bone marrow smear staining positive for iron. All analyses were performed at the Department of Clinical Chemistry, Capio Sankt Görans Hospital, with the exception of the bone marrow analyses, which were performed at the Department of Pathology, Capio Sankt Görans Hospital. Statistical analyses were conducted using the SigmaPlot 11 software package (Systat Software, San Jose, CA, USA). Quantitative variables were expressed as means \pm standard deviations. ESR was expressed as range.

\section{Results and Discussion}

The aim of this observational study was to characterize the anaemia in a population of anaemic patients with GCA and PMR. Mean $\mathrm{Hb}$ and TSAT were $102.3 \mathrm{~g} / \mathrm{L}$ and $9.7 \%$, respectively (Table 1) and all patients fulfilled the criterion for IRE, i.e. TSAT $<20 \%$ in combination with a bone marrow smear staining positive for iron. The reason for using this definition of IRE is that in patients who suffer from inflammatory diseases, the biochemical iron status is affected by acute-phase responses [14]. Under these circumstances, the best way to assess the iron status of an individual is to perform a bone marrow iron staining [15]. Thus, in the rheumatology setting, the optimal definition of IRE is probably a positive bone marrow iron staining in combination with TSAT $<20 \%$. Mean values for $\mathrm{MCV}, \mathrm{MCH}$, and sTfR were normal, whereas mean serum iron and TIBC were subnormal, and mean ferritin above its upper reference limit (Table 1). All six patients, whose mean age was 78 (range 60 - 85) years exhibited clinical and biochemical signs of active inflammation with a mean CRP of $58.7 \mathrm{mg} / \mathrm{L}$ and elevated ESR (range 27 - >100).It has recently been reported that the low TSAT in a population of elderly hospitalized anaemic patients with IRE was solely caused by a low serum iron concentration [16]. In contrast, in the present study, both mean serum iron and TIBC were subnormal. This is in line with the common finding that transferrin (transferrin $[\mathrm{g} / \mathrm{L}]=\mathrm{TICB}[\mu \mathrm{mol} / \mathrm{L}]$ divided by 25.1$)$ acts as a "negative" acute phase protein [17]. Anaemia is frequent in GCA and PMR at diagnosis [9-11], but there are no reports on the prevalence of IRE in these patients using the
Table 1. Haematological, biochemical iron data, CRP and ESR in anemic patients with GCA and PMR. Data are expressed as mean \pm SD. For ESR, data are expressed as range.

\begin{tabular}{cc}
\hline Variable & Value \\
\hline Age $($ years $)$ & $78 \pm 9$ \\
$\mathrm{Hb}(\mathrm{g} / \mathrm{L})$ & $102.3 \pm 6.1$ \\
$\mathrm{MCV}(\mathrm{Fl})$ & $92.8 \pm 9.5$ \\
$\mathrm{MCH}(\mathrm{pg})$ & $31.2 \pm 3.0$ \\
$\mathrm{Iron}(\mu \mathrm{mol} / \mathrm{L})$ & $4.4 \pm 2.5$ \\
$\mathrm{TIBC}(\mu \mathrm{mol} / \mathrm{L})$ & $44.0 \pm 5.3$ \\
$\mathrm{TSAT}(\%)$ & $9.7 \pm 4.8$ \\
Ferritin $(\mu \mathrm{g} / \mathrm{L})$ & $510 \pm 191$ \\
$\mathrm{CRP}(\mathrm{mg} / \mathrm{L})$ & $58.7 \pm 60.7$ \\
$\mathrm{ESR}(\mathrm{mm} / \mathrm{h})$ & $27->100$ \\
$\mathrm{STfR}(\mathrm{mg} / \mathrm{L})$ & $1.39 \pm 0.47$ \\
\hline
\end{tabular}

Abbreviations: $\mathrm{MCV}$, mean corpuscular volume; $\mathrm{MCH}$, mean corpuscular hemoglobin; TIBC, total iron binding capacity; TSAT, transferrin saturation; CRP, C-reactive protein; ESR, erythrocyte sedimentation rate; sTfR, soluble tranferrin receptor.

more strict definition of IRE, including a bone marrow iron staining, except from one small study in which $3 / 3$ anaemic GCA patients fulfilled this IRE definition [16]. In rheumatoid arthritis (RA), the prevalence of anaemia of chronic disease (ACD) is $30 \%$ to $49 \%[18,19]$, and the pathogenetic mechanisms behind ACD partly ovelap those in IRE $[1,20]$. In the study by Vreugdenhil and coworkers $30 \%$ of the RA patients exhibited ACD and their mean TSAT was $5 \%$. This, and the results from a study by Jeffrey [21], in which mean TSAT in anaemic RA patients was below $10 \%$, support the finding that IRE is common in rheumatic diseases. There are no published data on ESA treatment with or without iron supplementation or iron treatment alone in anaemic GCA and PMR patients. In rheumatoid arthritis (RA), several trials have shown that ESA treatment with or without iron supplementation increases $\mathrm{Hb}$ and quality of life [22-24]. In two of these trials [22,24], $88 \%$ and $82 \%$ of the patients, respectively, developed FID and exhibited a response to iron supplementation during ESA treatment. Furthermore, some reports indicate that parenteral iron alone can increase $\mathrm{Hb}$ levels in iron-replete anaemic RA patients [25, 26], although there are concerns that iron therapy in active RA can exacerbate the disease [27,28]. FID is common in the nephrology setting [6] and iv iron supplementation decreases the ESA requirement in CKD patients [29]. It has also been demonstrated that iv iron alone raises $\mathrm{Hb}$ in anaemic iron-replete patients with CKD [30,31]. In the trial by Mirescu and co-workers, iron treatment was associated with a $40 \%$ increase in the per- 
centage of patients with TSAT $>20 \%$ [31]. In the FAIRHF trial intravenous iron treatment of iron-deficient anaemic and non-anaemic patients diagnosed with congestive heart failure improved self-reported Patient Global Assessment and NYHA functional class compared to placebo [32]. However, in the above-mentioned trial, patients with IRE and non-IRE were not reported separately. In the haematology/oncology setting, three trials including anaemic patients suffering from cancer have shown that those with IRE have a better erythropoietic response when treated with ESA supplemented with iv iron than those receiving ESA only [33-35]. In the NIFe trial [34], all patients with biochemical signs of IRE at any time during the trial had an erythropoietic response to ESA plus iv iron, defined as an increase in $\mathrm{Hb}>20$ $\mathrm{g} / \mathrm{L}$, compared to $54 \%$ in the ESA only group. In the trial by Katriditou and co-workers [35], hypochromic erythrocytes $(\mathrm{HYPO} \%)<5 \%$ was identified as a predictive factor for response to ESA. Furthermore, IRE defined as $\mathrm{HYPO} \%>5 \%$ was an independent marker of response to iv iron supplementationfor patients receiving ESA [35].

\section{Conclusion}

In this study, 6/6 anaemic patients with GCA and PMR exhibited IRE, defined as a bone marrow smear staining positive for iron in combination with TSAT $<20 \%$. Larger studies are needed to determine the prevalence of IRE in GCA and PMR, but in view of the positive erythropoietic effects of ESA plus iron treatment or iron treatment alone in cardiology, haematology/oncology and nephrology settings, it would be interesting to evaluate the impact of ESA and/or iron treatment of anaemic GCA and PMR patients. Especially interesting is the finding that all patients in the present study exhibited IRE, as published trials in the haematology/oncology setting indicate that anaemic IRE patients respond favourably to ESA treatment supplemented with iv iron.

\section{Acknowledgements}

The author is the principal investigator in the FER-FIDCHEMO study (Clinical Trials. gov. Identifier: NCT1101399).

\section{REFERENCES}

[1] L. Goodnough, E. Nemeth and T. Ganz, "Detection, Evaluation, and Management of Iron-Restricted Erythropoiesis," Blood, Vol. 116, No. 23, 2010, pp. 4754-4761. doi:10.1182/blood-2010-05-286260

[2] E. Nemeth, S. Rivera, V. Gabayan, C. Keller, S. Taudorf, K. Pedersen and T. Ganz, "IL-6 Mediates Hypoferremia of Inflammation by Inducing the Synthesis of the Iron Regulatory Hormone Hepcidin," Journal of Clinical Investigation, Vol. 113, No. 9, 2004, pp. 1271-1276.
[3] E. Nemeth, M. Tuttle, J. Powelson, M. Vaughn, A. Donovan, D. McVey Ward, T. Ganz and J. Kaplan, "Hepcidin Regulates Cellular Iron Efflux by Binding to Ferroportin and Inducing Its Internalization," Science, Vol. 306, No. 5704, 2004, pp. 2090-2093. doi:10.1126/science. 1104742

[4] S. Rivera, L. Liu, E. Nemeth, V. Gabayan, O. Sorenson and T. Ganz, "Hepcidin Excess Induces the Sequestration of Iron and Exacerbates Tumor-Associated Anemia," Blood, Vol. 105, No. 4, 2005, pp. 1797-1802. doi:10.1182/blood-2004-08-3375

[5] L. Viatte, G. Nicolas, D.-Q. Lou, M. Bennoun, J.-C. Lebordes-Brion, F. Cannone-Hergaux, K. Schönig, H. Bujard, A. Kahn, N. Andrews and S. Vaulont, "Chronic Hepcidin Induction Causes Hypoferremia and Alters the Pattern of Cellular Iron Accumulation in Hemochromatotic Mice," Blood, Vol. 107, No. 7, 2006, pp. 2952-2958. doi:10.1182/blood-2005-10-4071

[6] F. Locatelli, A. Covic, K.-U. Eckardt, A. Wiecek, R. Wanholder and on Behalf of the ERA-EDTA Advisory Board, "Anemia Management in Patients with Chronic Kidney Disease: A Position Statement by the Anemia Working Group of European Renal Best Practice," Nephrology Dialysis Transplantation, Vol. 24, No. 2, 2009, pp. 348-354. doi:10.1093/ndt/gfn653

[7] T. Karlsson, "Effects of Iron Supplementation on Erythropoietic Response in Patients with Cancer-Associated Anemia Treated by Means of Erythropoietic Stimulating Agents," ISRN Hematology, Vol. 2011, No. 2011, 2011, Article ID: 108397. doi:10.1155/1759

[8] H. Bird, "Review of Diagnostic Criteria for Polymyalgia Rheumatica/Giant Cell Arteritis," Rheumatology, Vol. 44, No. S3, 2005, pp. iii2-iii3. doi:10.1093/rheumatology/keh731

[9] J. Jones and B. Hazleman, "Polymyalgia Rheumatica-A Difficult Diagnosis," The Journal of the Royal College of General Practitioners, Vol. 32, No. 226, 1981, pp. 286289.

[10] K. Wilske and L. Healey, "Polymyalgia Rheumatica," Annals of Internal Medicine, Vol. 66, No. 5, 1967, pp. 1069-1069.

[11] L. Healey and K. Wilske, "Anemia as a Presenting Manifestation of Giant Cell Arteritis," Arthritis \& Rheumatism, Vol. 14, No. 1, 1971, pp. 27-31. doi:10.1002/art.1780140105

[12] G. Hunder, D. Bloch, B. Michel, M. Stevens, W. Arend, L. Calabrese, S. Edworthy, A. Fauci, R. Leavitt, J. Lie, R. Lightfoot, A. Masi, D. McShane, J. Mills, S. Wallace and N. Zvaifer, "The American College of Rheumatology 1990 Criteria for the Classification of Giant Cell Arteritis," Arthritis and Rheumatism, Vol. 33, No. 8, 1990, pp. 1122-1128. doi:10.1002/art.1780330810

[13] R. Stasi, S. Amadori, T. Littlewood, E. Terzoli, A. Newland and D. Provan, "Management of Cancer-Related Anemia with Erythropoietic Agents: Doubts, Certainties, and Concerns," Oncologist, Vol. 10, No. 7, 2005, pp 539554. doi:10.1634/theoncologist.10-7-539

[14] M. Woorwood, "Laboratory Determination of Iron Status,” In: J. Brock, J. Halliday, M. Pippard and L. Powell, 
Eds., Iron Metabolism in Health and Disease, W. B. Saunders, London, 1994, pp. 449-476.

[15] A. Baer, E. Dessypris and B. Krantz, "The Pathogenesis of Anemia in Rheumatoid Arthritis: A Clinical and Laboratory Analysis," Seminars in Arthritis and Rheumatism, Vol. 19, No. 4, 1990, pp. 209-223.

doi:10.1016/0049-0172(90)90001-V

[16] T. Karlsson, "Iron-Restricted Erythropoiesis in a Population of Elderly Hospitalized Anemic Patients," Open Journal of Blood Disease, Vol. 2, No. 2, 2012, pp. 30-33. doi:10.4236/ojbd.2012.22006

[17] A. Erslev, “Anemia of Chronic Disease," In: E. Beutler, M. Lichtmann, B. Coller, T. Kipps and U. Seligsohn, Eds., Williams Hematology, 6th Edition, McGraw-Hill, New York, 2001, pp. 481-487.

[18] G. Vreugdenhil, A. Wognum, H. van Eik and A. Swaak, "Anaemia in Rheumatoid Arthritis: The Role of Iron, Vitamin B12, and Folic Acid Deficiency, and Erythropoietin Deficiency," Annals of the Rheumatic Diseases, Vol. 49, No. 2, 1990, pp. 93-98. doi:10.1136/ard.49.2.93

[19] H. Peeters, M. Jongen-Lavrencic, A. Raja, H. Ramdin, G. Vreugdenhil, F. Breedveld and A. Swaak, "Course and Characteristics of Anaemia in Patients with Rheumatoid Arthritis of Recent Onset," Annals of the Rheumatic Diseases, Vol. 55, No. 3, 1996, pp. 162-168. doi:10.1136/ard.55.3.162

[20] C. Thomas and L. Thomas, "Anemia of Chronic Disease: Pathophysiology and Laboratory Diagnosis," Laboratory Hematology, Vol. 11, No. 1, 2005, pp. 14-23. doi:10.1532/LH96.04049

[21] M. Jeffrey, "Intravenous Iron in Rheumatoid Arthritis: Possible Prognostic Factors," British Medical Journal, Vol. 2, 1953, pp. 912-913. doi:10.1136/bmj.2.4842.912

[22] H. Peeters, M. Jongen-Lavrencic, G. Vreugdenhill and A. Swaak, "Effect of Recombinant Human Erythropoietin on Anaemia and Disease Activity in Patients with Rheumatoid Arthritis and Anaemia of Chronic Disease: A Randomized Placebo Controlled Double Blind 52 Weeks Clinical Trial," Annals of the Rheumatic Diseases, Vol. 55, No. 10, 1996, pp. 739-744. doi:10.1136/ard.55.10.739

[23] H. Peeters, M. Jongen-Lavrencic, C. Bakker, G. Vreugdenhill, F. Breedveld and A. Swaak, "Recombinant Human Erythropoietin Improves Health-Related Quality of Life in Patients with Rheumatoid Arthritis and Anaemia of Chronic Disease: Utility Measures Correlate Strongly with Disease Activity Measures," Rheumatology International, Vol. 18, No. 5-6, 1999, pp. 201-206. doi:10.1007/s002960050085

[24] J. Kaltwasser, U. Kessler, R. Gottschalk, G. Stucki and B. Möller, "Effect of Recombinant Human Erythropoietin and Intavenous Iron on Anemia and Disease Activity in Rheumatoid Arthritis," Journal of Rheumatology, Vol. 28, No. 11, 2001, pp. 2430-2436.

[25] J. Richmond, L. Roy, D. Gardner, W. Alexander and J. Duthie, "Nature of Anaemia in Rheumatoid Arthritis IV. Effects of the Intravenous Administration of Saccharated Oxide of Iron," Annals of the Rheumatic Diseases, Vol. 17, No. 4, 1958, pp. 406-415. doi:10.1136/ard.17.4.406

[26] D. Bentley and P. Williams, "Pareneteral Iron Therapy in the Anemia of Rheumatoid Arthritis," Rheumatology, Vol. 21, No. 2, 1982, pp. 88-92.

doi:10.1093/rheumatology/21.2.88

[27] P. Reddy and M. Lewis, "The Adverse Effect of Intravenous Iron-Dextran in Rheumatoid Arthritis," Arthritis \& Rheumatism, Vol. 12, No. 4, 1969, pp. 454-457. doi:10.1002/art.1780120413

[28] D. Blake, J. Lunec, M. Ahern, E. Ring, J. Bradfield and J. Gutteridge, "Effect of Intravenous Iron Dextran on Rheumatoid Synovitis," Annals of the Rheumatic Diseases, Vol. 44, No. 3, 1985, pp. 183-188. doi:10.1136/ard.44.3.183

[29] S. Fishbane, G. Frei and J. Maesaka, "Reduction in Recombinant Human Erythropoietin Doses by the Use of Chronic Intravenous Iron Supplementation," American Journal of Kidney Diseases, Vol. 26, No. 1, 1995, pp. 4146. doi:10.1016/0272-6386(95)90151-5

[30] D. Silverberg, A. Iaina, G. Peer, E. Kaplan, B. A. Levi, N. Frank, S. Steinbruch and M. Blum, "Intravenous Iron Supplementation for the Treatment of the Anemia of Moderate to Severe Chronic Renal Failure Patients Not Receiving Dialysis," American Journal of Kidney Diseases, Vol. 27, No. 2, 1996, pp. 234-238. doi:10.1016/S0272-6386(96)90546-6

[31] G. Mirescu, L. Garneata, C. Capusa and N. Ursea, "Intravenous Iron Supplementation for the Treatment of Anaemia in Pre-Dialyzed Chronic Renal Failure Patients," Nephrology Dialysis Transplantation, Vol. 21, No. 1, 2006, pp. 120-124. doi:10.1093/ndt/gfi087

[32] S. Anker, J. CominColet, G. Filippatos, R. Willenheimer, K. Dickstein, H. Drexler, T. Luscher, B. Bart, W. Banasiak, J. Niegowska, B.-A. Kirwan, C. Mori, B. von EisenhartRothe, M. S. Pocock, P. Poole-Wilson and P. Ponikowski, "Ferric Carboxymaltose in Patients with Heart Failure and Iron Deficiency," New England Journal of Medicine, Vol. 361, No. 25, 2009, pp. 2436-2448. doi:10.1056/NEJMoa0908355

[33] D. Henry, N. Dahl, M. Auerbach, S. Tchekmedyian and L. Laufmane, "Intravenous Ferric Gluconate Significantly Improves Response to Epoetinalfa versus Oral or No Iron in Anemic Patients with Cancer Receiving Chemotherapy," Oncologist, Vol. 12, No. 2, 2007, pp. 231-242. doi:10.1634/theoncologist.12-2-231

[34] M. Hedenus, G. Birgegård, P. Näsman, L. Ahlberg, T. Karlsson, B. Lauri, J. Lundin, G. Lärfars and A. Österborg, "Addition of Intravenous Iron to Epoetin Beta Increases Hemoglobin Response and Decreases Epoetin Dose Requirement in Anemic Patients with Lymphoproliferative Malignancies: A Randomized Multicenter Study," Leukemia, Vol. 21, No. 4, 2007, pp. 627-632.

[35] E. Katodritou, E. Terpos, K. Zervas, M. Speletas, D. Kapetanos, C. Kartsios, E. Verrou, A. Banti, S. Effraimidou and J. Christakis, "Hypochromic Erythrocytes (\%): A Reliable Marker for Recognizing Iron-Restricted Erythropoiesis and Predicting Response to Erythropoietin in Anemic Patients with Myeloma and Lymphoma," Annals of Hematology, Vol. 86, No. 5, 2007, pp. 369-376. doi:10.1007/s00277-007-0258-X 